\title{
Short communication: Recursive model approach to traits defined as ratios: Genetic parameters and breeding values
}

\author{
J. Jamrozik, ${ }^{*}{ }^{1}$ J. Johnston, ${ }^{*}$ P. G. Sullivan, ${ }^{*}$ and F. Miglior ${ }^{*} \dagger$ \\ ${ }^{*}$ Canadian Dairy Network, Guelph, Ontario, Canada, N1K 1 E5 \\ †Centre for Genetic Improvement of Livestock, Department of Animal Biosciences, University of Guelph, Guelph, Ontario, Canada, N1G 2W1
}

\begin{abstract}
A novel method for analysis of ratio traits $\left(Y_{2} / Y_{1}\right)$ is proposed. Utilizing a recursive modeling approach, a proxy for $Y_{2} / Y_{1}$ can be postulated as $Y_{2}-\lambda \times Y_{1}$ (i.e., $Y_{2}$ adjusted for the effect of $Y_{1}$ ), where $\lambda$ is a structural parameter describing an effect of change in phenotype of $\mathrm{Y}_{2}$ caused by the phenotype of $\mathrm{Y}_{1}$. Estimates of parameters (direct effect parameters) for the recursive model $\mathrm{Y}_{1} \rightarrow \mathrm{Y}_{2}$ can be derived from parameters of an equivalent 2-trait mixed effects model for $Y_{1}$ and $\mathrm{Y}_{2}$, using linear (location) and quadratic (dispersion) transformations. The method is illustrated with an application for milk fat (protein) content, calculated as a ratio of fat (protein) and milk yields $(\mathrm{kg})$, in the context of genetic parameters estimation and genetic evaluation via the Canadian test-day model for production traits. Results indicated the potential usefulness of the proposed approach for analysis of any $\mathrm{Y}_{2} / \mathrm{Y}_{1}$ (or $\mathrm{Y}_{2}$ adjusted for the effect of $\mathrm{Y}_{1}$ ) type of trait utilizing standard multiple-trait modeling techniques for $Y_{1}$ and $\mathrm{Y}_{2}$.
\end{abstract}

Key words: genetic parameters, ratio traits, recursive model

\section{Short Communication}

Many traits in animal breeding are defined as a ratio of 2 other (usually correlated) biological traits. Examples are fat or protein content in milk, feed conversion ratio, or other traits related to feed efficiency. The purpose of creating a ratio is to adjust the numerator trait to a variable that is free of the influence of the denominator. A problem with these traits is that they are not normally (or standard) distributed, and thus do not follow assumptions of standard analyses (i.e., testing of hypotheses, likelihood based methods, Bayesian inference). In fact, the distribution of a ratio of 2 normally

Received October 19, 2016.

Accepted January 19, 2017.

${ }^{1}$ Corresponding author: jjamrozi@uoguelph.ca distributed variables is known (i.e., Cauchy) only when these 2 variables are uncorrelated. Estimated breeding values of ratio traits are often derived ad hoc from EBV of their components in a simplified way; examples are fat and protein content traits in the Canadian test-day model (CTDM; Schaeffer et al., 2000).

Structural equation models (Gianola and Sorensen, 2004) allow fitting causal relationships between phenotypes, in addition to a regular co-variance structure in the multiple-trait model (MTM). Recursive models (RM) form a category of structural equation models in which causal links do not include circular or reciprocal effects. A fully recursive model with restrictions on residual co-variances is statistically equivalent to the standard MTM. Parameters of RM and MTM have different interpretations (Valente et al., 2013). In RM, they represent effects acting directly on each trait without mediation by other traits in the model. Parameters of MTM represent an overall effect on each trait i.e., combining direct and all indirect effects generated by RM. Causal links among traits can be postulated (or assumed) to be known for many scenarios. Parameters of standard MTM fitted to these traits can then be transformed to RM parameters under the assumption of known causal structure (Jamrozik and Miller, 2014).

The objectives of this study were to derive genetic parameters and EBV for a proxy of a trait defined as a ratio, using the RM approach. Equivalence of RM and MTM would then simplify the analyses to a standard multiple-trait model for the ratio trait components.

We propose here, that inferences related to a trait defined as a ratio of 2 phenotypes $\left(\mathbf{Y}_{2} / \mathbf{Y}_{1}\right)$ can be derived from a $R M$ for $Y_{1}$ and $Y_{2}$, assuming a phenotypic link from $\mathrm{Y}_{1}$ to $\mathrm{Y}_{2}\left(\mathrm{Y}_{1} \rightarrow \mathrm{Y}_{2}\right)$ :

$$
\begin{gathered}
\mathrm{Y}_{1}=\text { fixed }_{1}+\text { random }_{1}+\mathrm{e}_{1} \\
\mathrm{Y}_{2}=\lambda \times \mathrm{Y}_{1}+\text { fixed }_{2}+\text { random }_{2}+\mathrm{e}_{2}
\end{gathered}
$$

with $\lambda$ being a recursive coefficient parameter (effect of change in $\mathrm{Y}_{2}$ caused by the phenotype of $\mathrm{Y}_{1}$; fixed, random, and e denote fixed effects, random effects, and 
residual term of the model, respectively). It should be noted that the assumption of recursion from $Y_{1}$ to $Y_{2}$ is strictly technical (i.e., driven by a definition of a ratio trait), and thus it does not imply a simple biological (causal) relationship between these 2 traits. The RM approach presented in this paper could alternatively be considered as a regular MTM, in which phenotypes of one trait $\left(\mathrm{Y}_{2}\right)$ are adjusted for phenotypes of the other trait $\left(\mathrm{Y}_{1}\right)$ in a linear manner via residual regression. If there is, contrary to the assumptions, no causal (biological) link from $Y_{1}$ to $Y_{2}$, recursive coefficient $\lambda$ can simply be interpreted as a regression coefficient, free of its causal meaning.

Linear function $Y_{2}-\lambda \times Y_{1}$ describes $Y_{2}$ adjusted for the phenotypic effect of $Y_{1}$ (e.g., fat yield phenotypically adjusted for milk production). Estimates of system parameters for $\mathrm{Y}_{2}-\lambda \times \mathrm{Y}_{1}$ from the RM [1] (e.g., breeding values, heritability) can therefore be considered as parameters for a proxy of $\mathrm{Y}_{2} / \mathrm{Y}_{1}$.

Parameters of the recursive model can be derived from parameters of an equivalent MTM, following Jamrozik and Miller (2014). Let the MTM for 2 traits be represented as

$$
\mathbf{y}_{\mathrm{i}}=\mathbf{X}_{\mathrm{i}} \mathbf{b}^{*}+\mathbf{u}_{\mathrm{i}}^{*}+\mathbf{e}_{\mathrm{i}}^{*}
$$

where $\mathbf{y}_{\mathrm{i}}$ is a vector of observations for traits in subject $\mathbf{i}, \mathbf{b}^{*}$ is a vector of fixed effects, $\mathbf{u}_{\mathbf{i}}^{*}$ is a vector of additive genetic effects, $\mathbf{e}_{i}^{*}$ is a vector of residuals, and $\mathbf{X}_{\mathrm{i}}$ denotes an incidence matrix. Vectors $\mathbf{u}_{i}{ }^{*}$ and $\mathbf{e}_{i}{ }^{*}$ are assumed to follow a joint normal distributions with mean 0 and $\operatorname{var}\left(\mathbf{u}_{\mathrm{i}}{ }^{*}\right)=\mathbf{G}^{*}$ and $\operatorname{var}\left(\mathbf{e}_{\mathrm{i}}{ }^{*}\right)=\mathbf{R}^{*}=\left[\mathrm{r}^{*}{ }_{\mathrm{ij}}\right]$. Assume further that $\boldsymbol{\Lambda}=\left[\begin{array}{cc}1 & 0 \\ -\lambda & 1\end{array}\right]$ defines a causal structure for phenotypes. The RM equivalent to [2] is

$$
\Lambda \mathbf{y}_{\mathrm{i}}=\mathbf{X}_{\mathrm{i}} \mathbf{b}+\mathbf{u}_{\mathrm{i}}+\mathbf{e}_{\mathrm{i}}
$$

with

$$
\begin{aligned}
\operatorname{var}\left(\mathbf{u}_{\mathrm{i}}\right) & =\mathbf{G}, \operatorname{var}\left(\mathbf{e}_{\mathrm{i}}\right)=\mathbf{R} \text { (diagonal matrix), and } \\
\mathbf{R}^{*} & =\boldsymbol{\Lambda}^{-1} \mathbf{R} \boldsymbol{\Lambda}^{,-1}, \mathbf{G}^{*}=\boldsymbol{\Lambda}^{-1} \mathbf{G} \boldsymbol{\Lambda}^{\prime-1} \\
\mathbf{b}^{*} & =\boldsymbol{\Lambda}^{-1} \mathbf{b}, \mathbf{u}_{\mathrm{i}}^{*}=\boldsymbol{\Lambda}^{-1} \mathbf{u}_{\mathrm{i}}, \mathbf{e}_{\mathrm{i}}^{*}=\boldsymbol{\Lambda}^{-1} \mathbf{e}_{\mathrm{i}}
\end{aligned}
$$

After fitting model [2], parameters of [3] can be derived using $\lambda=\mathrm{r}_{12} * / \mathrm{r}_{11} *$ and relationships in [4]. In particular, $\mathbf{u}_{\mathrm{i}}{ }^{\prime}=\left[\mathrm{u}_{\mathrm{i} 1}{ }^{*}, \mathrm{u}_{\mathrm{i} 2}{ }^{*}-\lambda \mathrm{u}_{\mathrm{i} 1}{ }^{*}\right]^{\prime}$. Here, in the scope of RM, $\mathrm{u}_{\mathrm{i} 2}{ }^{*}-\lambda \mathrm{u}_{\mathrm{i} 1} *$ is a direct genetic effect on trait 2 (direct), and $\mathrm{u}_{\mathrm{i} 2} *-\left(\mathrm{u}_{\mathrm{i} 2} *-\lambda \mathrm{u}_{\mathrm{i} 1} *\right)=\lambda \mathrm{u}_{\mathrm{i} 1} *$ represents the indirect genetic effect on trait 2 mediated by trait 1 (indirect). The same applies to all other parameters of [3], where direct and indirect effects (or co-variance components) of the RM can be expressed as simple linear (quadratic) functions of MTM parameters. This approach can be easily generalized to other models (e.g., maternal effects model) and recursive scenarios including heterogeneous structural coefficients or more traits with known (or assumed) recursive structure $(\boldsymbol{\Lambda})$. The RM with heterogeneous structural coefficients, however, will only be an approximation when recursive coefficients are derived from a standard MTM, due to heterogeneity of genetic (and possibly other) population co-variances generated by heterogeneous $\Lambda$.

The method for RM-derived proxies of the ratio traits will be illustrated through the application to CTDM for production traits (Schaeffer et al., 2000). This is a multiple-trait random regression model, in which milk, fat, and protein test-day yields $(\mathrm{kg})$ in the first 3 lactations from 5 to 305 DIM are simultaneously

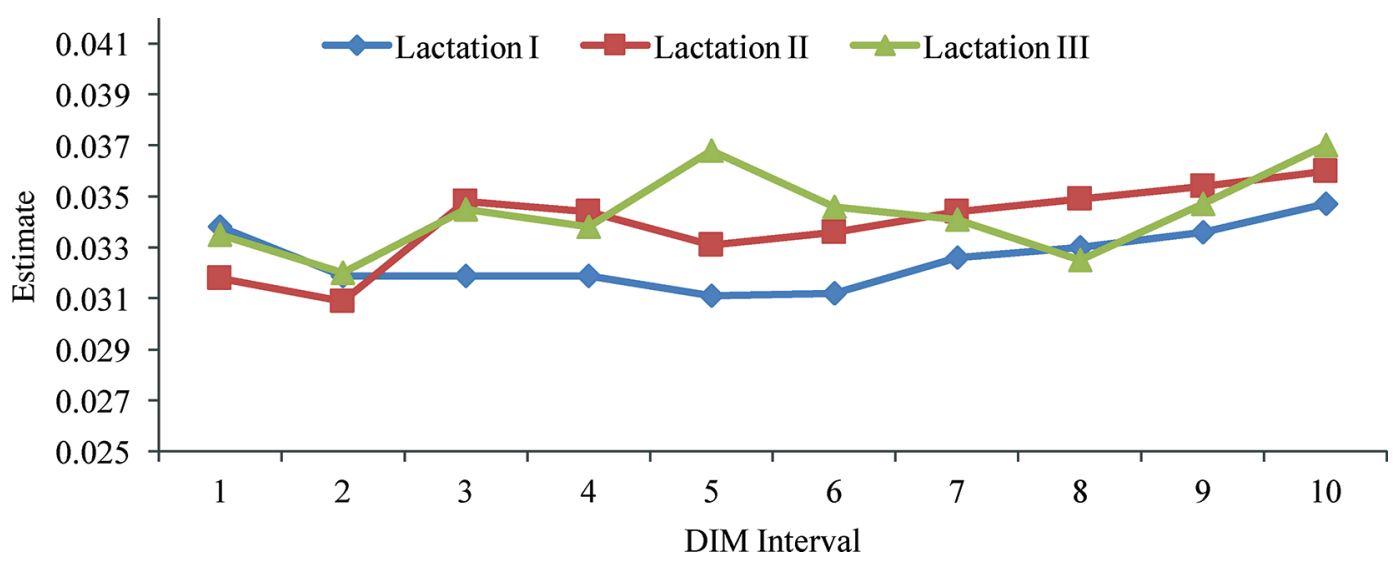

Figure 1. Estimates of recursive coefficients $(\lambda)$ for milk $\rightarrow$ fat in 10 DIM intervals from 5 to 305, by lactation. Standard deviations of estimates ranged from 0.0005 to 0.0017 . Color version available online. 


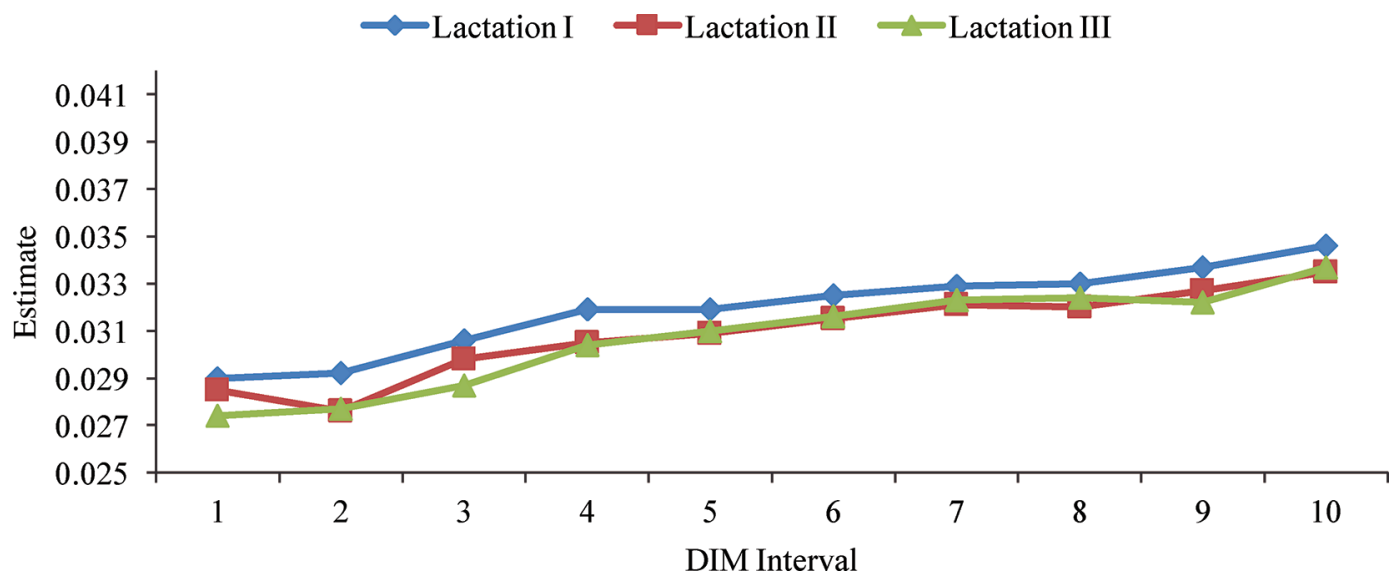

Figure 2. Estimates of recursive coefficients $(\lambda)$ for milk $\rightarrow$ protein in 10 DIM intervals from 5 to 305, by lactation. Standard deviations of estimates ranged from 0.0001 to 0.0005 . Color version available online.

analyzed for genetic evaluation purposes. Estimated breeding values for fat content (fat \%) and protein content (protein \%) (defined as a ratio of the respective milk component yield to the total milk yield) are then indirectly derived using a scaled (by phenotypic means) ratio of EBV for yields. This approach generates approximate evaluations for the contents (i.e., not necessarily holding BLUP properties). One alternative would be to apply an additional analysis for fat and protein contents, thus generating EBV for fat and protein percentages in a direct way. This, however, will substantially increase resources (i.e., computing time) that are needed for genetic evaluation.
Another less costly approach is to apply RM with assumed phenotypic links from milk to fat and protein, and to define

$$
\begin{aligned}
\text { Fat-direct } & =\text { fat }-\lambda_{\text {Fat } / \text { Milk }} \times \text { milk, and } \\
\text { Protein-direct } & =\text { protein }-\lambda_{\text {Protein/Milk }} \times \text { milk, }
\end{aligned}
$$

as proxies for fat $\%$ and protein $\%$; where milk, fat, and protein are yields for respective traits $(\mathrm{kg})$, and $\lambda$ are RM coefficients from milk to a given component trait. Again, the assumption of phenotypic links between milk and fat (protein) has to be considered only for the pur-

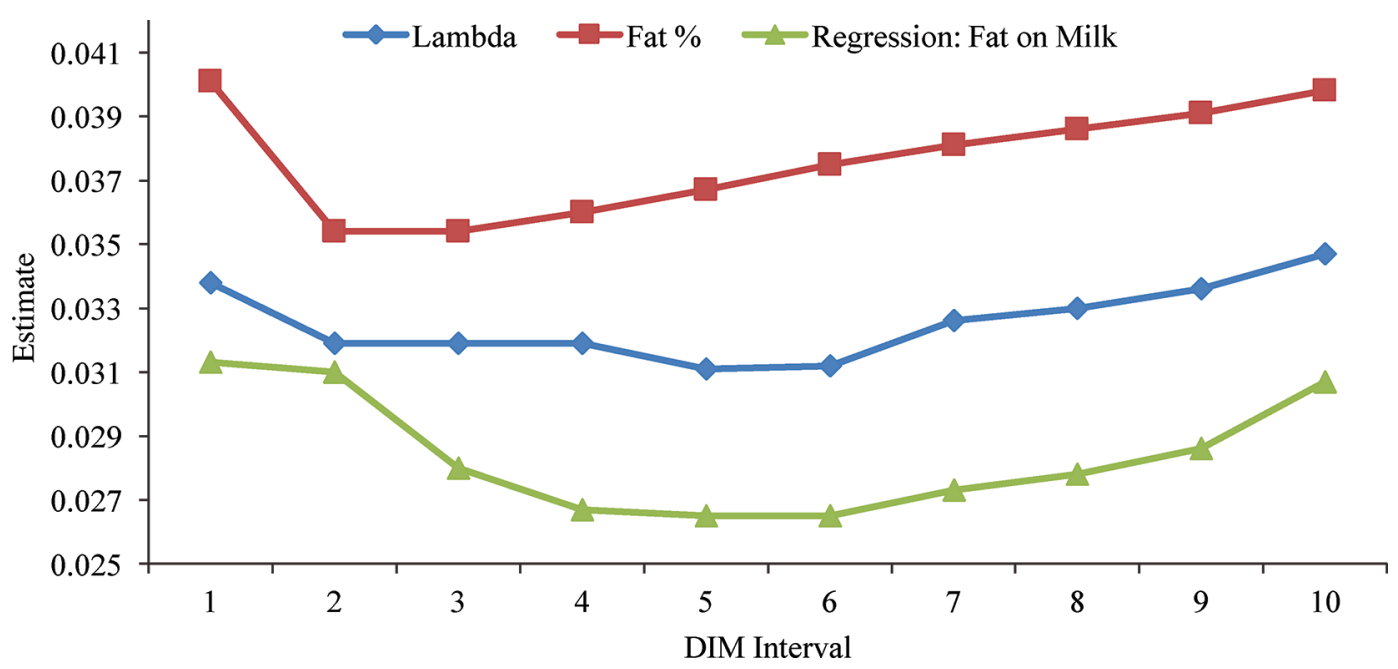

Figure 3. Estimates of recursive coefficients $(\lambda)$ for milk $\rightarrow$ fat (lambda), average fat content (fat \%) and regression coefficients of fat yield on milk yield (regression: fat on milk) in 10 DIM intervals from 5 to 305 of the first lactation. Color version available online. 
Table 1. Estimates of genetic parameters

\begin{tabular}{|c|c|c|c|c|}
\hline Parameter & Trait & Lactation I & Lactation II & Lactation III \\
\hline \multirow{4}{*}{ Heritability } & Fat $\%$ & 0.50 & 0.49 & 0.46 \\
\hline & Fat-direct $^{1}$ & 0.44 & 0.39 & 0.36 \\
\hline & Protein $\%$ & 0.58 & 0.57 & 0.55 \\
\hline & Protein-direct $^{2}$ & 0.59 & 0.55 & 0.56 \\
\hline \multirow[t]{6}{*}{ Genetic correlation } & Milk $(\mathrm{kg})-$ Fat $(\mathrm{kg})$ & 0.43 & 0.41 & 0.40 \\
\hline & Milk (kg) - Protein $(\mathrm{kg})$ & 0.84 & 0.83 & 0.81 \\
\hline & Milk (kg) - Protein \% & -0.50 & -0.44 & -0.38 \\
\hline & Milk $(\mathrm{kg})$ - Protein-direct & -0.48 & -0.36 & -0.33 \\
\hline & Fat $(\mathrm{kg})-$ Fat-direct & 0.63 & 0.66 & 0.67 \\
\hline & Protein $(\mathrm{kg})$ - Protein-direct & 0.09 & 0.23 & 0.29 \\
\hline
\end{tabular}

${ }^{1}$ Fat-direct $=$ fat $-\lambda_{\text {Fat } / \text { Milk }} \times$ milk, where $\lambda_{\text {Fat } / \text { Milk }}$ is a recursive coefficient parameter from milk to fat.

${ }^{2}$ Protein-direct $=$ protein $-\lambda_{\text {Protein/Milk }} \times$ milk, where $\lambda_{\text {Protein/Milk }}$ is a recursion coefficient parameter from milk to protein.

pose of the method, and does not necessary postulate a meaningful causal interpretation of relationships between traits. Fat-direct and protein-direct are adjusted for milk yield, and thus could serve as proxies for fat $\%$ and protein \%. Co-variance components (and genetic parameters) for fat-direct and protein $\%$, as well as EBV for these traits, can be derived from the MTM parameters for milk, fat, and protein, using transformations as described earlier, with $\lambda_{\text {Fat/Milk }}$ and $\lambda_{\text {Protein/Milk }}$ calculated from residual co-variance components of the MTM.

The residual co-variance structure in CTDM is assumed heterogeneous in 10 DIM intervals. Thus, the equivalent recursive model assumed a phenotypic link from milk to fat (or protein) with heterogeneous coefficients across lactations, and across 10 DIM intervals within each lactation. Co-variance components for milk, fat and protein for Canadian Holsteins were from Johnston et al. (2015). Parameters for fat \% and protein $\%$ were estimated in a separate analysis with CTDM applied to milk yield and fat and protein contents. For simplicity, within-lactation averages of recursive parameters $(\lambda)$ were used for transformations involving co-variance components. In addition, for the same reason, average within- and across-lactations $\lambda$ were applied to EBV. As previously stated, an equivalent MTM would require heterogeneous genetic (and other) co-variance structures. This was not attempted in this study and thus the equivalence between RM and MTM with respect to CTDM was not perfect. Our experience, however, indicated that ignoring heterogeneity of a nonresidual effect in the MTM would not lead to serious biases (Jamrozik et al., 2010).

Estimates of structural coefficients $(\lambda)$ from milk to fat and protein yields are in Figures 1 and 2, respectively. An across- and within-lactation heterogeneity of structural coefficients is exhibited for both traits. Note that the estimates of structural coefficients were not the same as the phenotypic average of fat \% (protein $\%$ ) or the phenotypic regression of milk yield on fat \% (protein \%), as illustrated for fat \% in Figure 3.

Estimates of selected genetic parameters for fat-direct and protein-direct, as well as milk, fat, protein yields and fat $\%$ and protein $\%$, are in Table 1 . All traits

Table 2. Summary statistics for official Holstein sire $(\mathrm{n}=11,723)$ EBV for combined (over lactations) milk $(\mathrm{kg})$, fat $(\mathrm{kg})$, protein $(\mathrm{kg})$, fat $\%$, protein $\%$, fat-direct, ${ }^{1}$ and protein-direct ${ }^{2}$

\begin{tabular}{lcccc}
\hline Trait & Mean & SD & Minimum & Maximum \\
\hline Milk $(\mathrm{kg})$ & $-1,035$ & 1,070 & $-3,981$ & 3,191 \\
Fat $(\mathrm{kg})$ & -32.3 & 37.4 & -143.0 & 135.0 \\
Protein $(\mathrm{kg})$ & -33.2 & 34.8 & -126.0 & 102.0 \\
Fat \% & 0.06 & 0.23 & -0.95 & 1.29 \\
Protein $\%$ & 0.01 & 0.10 & -0.52 & 0.54 \\
Fat-direct & 2.3 & 22.7 & -104.7 & 117.9 \\
Protein-direct & -1.5 & 10.8 & -61.0 & 58.7 \\
\hline
\end{tabular}

${ }^{1}$ Fat-direct $=$ fat $-\lambda_{\text {Fat } / \text { Milk }} \times$ milk, where $\lambda_{\text {Fat } / \text { Milk }}$ is a recursive coefficient parameter from milk to fat.

${ }^{2}$ Protein-direct $=$ protein $-\lambda_{\text {Protein/Milk }} \times$ milk, where $\lambda_{\text {Protein/Milk }}$ is a recursion coefficient parameter from milk to protein. 
Table 3. Correlations among official sire $(\mathrm{n}=11,723) \mathrm{EBV}$ for combined (over lactations) milk $(\mathrm{kg})$, fat $(\mathrm{kg})$, protein $(\mathrm{kg})$, fat \%, protein \%, fat-direct, ${ }^{1}$ and protein-direct ${ }^{2}$

\begin{tabular}{lcccrrr}
\hline & Milk $(\mathrm{kg})$ & Fat $(\mathrm{kg})$ & Protein $(\mathrm{kg})$ & Fat \% & Protein \% & Fat-direct \\
\hline Milk $(\mathrm{kg})$ & & 0.61 & 0.90 & -0.50 & -0.33 & -0.41 \\
Fat $(\mathrm{kg})$ & 0.61 & & 0.75 & 0.38 & 0.22 & 0.47 \\
Protein $(\mathrm{kg})$ & 0.90 & 0.75 & & -0.24 & 0.11 & -0.14 \\
Fat \% & -0.50 & 0.38 & -0.24 & & 0.63 & 0.99 \\
Protein \% & -0.33 & 0.22 & 0.11 & 0.63 & & 0.27 \\
Fat-direct & -0.41 & 0.47 & -0.14 & 0.99 & 0.63 & 0.57 \\
Protein-direct & -0.17 & 0.34 & 0.27 & 0.57 & 0.99 & 0.99 \\
\hline
\end{tabular}

${ }^{1}$ Fat-direct $=$ fat $-\lambda_{\text {Fat } / \text { Milk }} \times$ milk, where $\lambda_{\text {Fat } / \text { Milk }}$ is a recursive coefficient parameter from milk to fat.

${ }^{2}$ Protein-direct $=$ protein $-\lambda_{\text {Protein/Milk }} \times$ milk, where $\lambda_{\text {Protein/Milk }}$ is a recursion coefficient parameter from milk to protein.

were average yield (\%) for 5 to 305 DIM of lactation. Overall, relatively good agreement between parameters involving "direct" and "\%" traits was observed for both milk components.

National genetic evaluations for Holstein sires with official proofs in December 2015 are summarized in Table 2, and correlations among EBV for milk, fat, protein, fat $\%$, protein $\%$, fat-direct, and protein-direct are presented in Table 3. All traits were expressed as average yield (\%) for 5 to 305 DIM across 3 lactations. Fat-direct and protein-direct constituted a fraction (independent of milk yield) of respective yield traits. There was almost perfect agreement in ranking of sires for "direct" and "\%" for both traits.

Linear proxies for ratio traits have been proposed for other animal breeding applications. Yang et al. (2008) suggested using $\mathrm{Z}=\mathrm{X}-\alpha \mathrm{Y}$, where the ratio of population means for $\mathrm{X}$ and $\mathrm{Y} ; \alpha=\mu_{\mathrm{X}} / \mu_{\mathrm{Y}}$ as a phenotype for an analysis to detect significant QTL for $\mathrm{X} / \mathrm{Y}$. Simulation showed superiority of this approach to a QTL search applied directly to phenotypes for X/Y. Gunsett (1984) demonstrated that selection based on a linear index with $\mathrm{I}=\mathrm{b}_{\mathrm{X}} \times \mathrm{X}+\mathrm{b}_{\mathrm{Y}} \times \mathrm{Y}$ (maximizing the correlation between the index and a genotype for $\mathrm{X} / \mathrm{Y}$, where $\mathrm{b}_{\mathrm{X}}$ and $\mathrm{b}_{\mathrm{Y}}$ are selection index weights) was more efficient then direct selection on a ratio. Gunsett (1984) emphasized that direct selection on a ratio is complicated by "the disproportionate fashion by which selection pressure is exerted on the component traits."

Application of RM to derive parameters for a trait defined as a ratio of another (correlated) phenotype was illustrated by fat $\%$ and protein $\%$ in the scope of a random regression test-day model. In fact, milk yield and solid contents (\%) are directly measured phenotypes in dairy cattle. Because fat and protein $(\mathrm{kg})$ are traits with more economic importance in several breeding programs, these are the traits (derived from milk and solid contents) for which genetic evaluation is primarily performed. This scenario, however, served only for illustration purposes and it does not, in any way, limit the potential usefulness of the proposed method. Better statistical properties of EBV defined as a linear function of component traits might improve other aspects of genetic evaluations for ratio-defined traits, such as deregression of EBV to generate more accurate phenotypes for genomic evaluation. Estimation of accuracy (or reliability) for EBV expressed as a linear combination of components is also straightforward. Suitable transformation of EBV for a direct trait is possible to express evaluation results on a scale similar to that of a corresponding component trait.

The proposed method for analysis of ratio traits can be used for any correlated traits $\mathrm{Y}_{1}$ and $\mathrm{Y}_{2}$. The method can also be applied to generate parameters of $\mathrm{Y}_{2}$ adjusted for the effect of correlated $\mathrm{Y}_{1}$, an example of which could be animal survival adjusted for the level of production (i.e., functional survival). The method does not require analysis of phenotypes for $\mathrm{Y}_{2} / \mathrm{Y}_{1}$; covariance components and EBV for a $\mathrm{Y}_{2} / \mathrm{Y}_{1}$ proxy derived from $\mathrm{RM}$ are simple and well defined by-products of regular MTM parameters for $\mathrm{Y}_{1}$ and $\mathrm{Y}_{2}$.

\section{ACKNOWLEDGMENTS}

This research is part of the Efficient Dairy Genome Project, funded by Genome Canada (Ottawa, Canada), Genome Alberta (Calgary, Canada), Ontario Genomics (Toronto, Canada), Alberta Livestock and Meat Agency (Edmonton, Canada), Ontario Ministry of Research and Innovation (Toronto, Canada), Ontario Ministry of Agriculture, Food and Rural Affairs (Guelph, Canada), Canadian Dairy Network (Guelph, Canada), GrowSafe Systems (Airdrie, Canada), Alberta Milk (Edmonton, Canada), Department of Development, Jobs, Transport and Resources (Australia), Scotland's Rural College (Edinburgh, UK), USDA Agricultural Research Service (United States), Qualitas AG (Switzerland). Helpful suggestions from L. R. Schaeffer (University of Guelph, Guelph, Canada) and 3 anonymous reviewers are greatly appreciated. 


\section{REFERENCES}

Gianola, D., and D. Sorensen. 2004. Quantitative genetic models for describing simultaneous and recursive relationships between phenotypes. Genetics 167:1407-1424.

Gunsett, F. C. 1984. Linear index selection to improve traits defined as ratios. J. Anim. Sci. 59:1185-1193.

Jamrozik, J., J. Bohmanova, and L. R. Schaeffer. 2010. Relationships between milk yield and somatic cell score in Canadian Holsteins from simultaneous and recursive random regression models. J. Dairy Sci. 93:1216-1233.

Jamrozik, J., and S. P. Miller. 2014. Partitioning of multiple-trait model parameters with respect to phenotypic recursion: Case study of birth weight and calving ease in Canadian Simmentals. Proc. 10th World Congr. Genet. Appl. Livest. Prod., Vancouver, Canada Accessed Oct. 18, 2016. https://asas.org/docs/default-source/ wcgalp-proceedings-oral/247_paper_8768_manuscript_243_0 pdf? sfvrsn $=2$.

Johnston, J., G. J. Kistemaker, and J. Jamrozik. 2015. Estimation of genetic parameters for SCS independent of production. Research Report to the GEB, October 2015. Accessed Dec. 6, 2016. https:// www.cdn.ca/Articles/GEBOCT2015/3_SCS_Independent_of_ Production - Report 1.pdf.

Schaeffer, L. R., J. Jamrozik, G. J. Kistemaker, and B. J. Van Doormaal. 2000. Experience with a test day model. J. Dairy Sci. 83:1135-1144.

Valente, B. D., G. J. M. Rosa, D. Gianola, X. L. Wu, and K. Weigel. 2013. Is structural equation modeling advantageous for the genetic improvement of multiple traits? Genetics 194:561-572.

Yang, R., J. Li, and S. Xu. 2008. Mapping quantitative trait loci for traits defined as ratios. Genetica 132:323-329. 